\title{
Crimean-Congo haemorrhagic fever presenting with undiagnosed chronic myeloid leukaemia ${ }^{\dagger}$
}

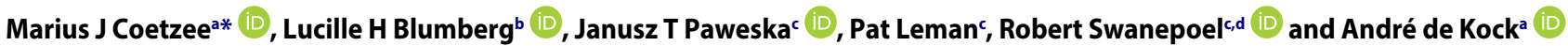 \\ aDepartment of Haematology and Cell Biology, University of the Free State and National Health Laboratory Service, Bloemfontein, South Africa \\ ${ }^{b}$ Centre for Emerging and Zoonotic Diseases, National Institute for Communicable Diseases of the National Health Laboratory Service, \\ Johannesburg, South Africa \\ 'Special Pathogens Unit, National Institute for Communicable Diseases of the National Health Laboratory Service, Johannesburg, South Africa \\ ${ }^{d}$ Department of Veterinary Tropical Diseases, University of Pretoria, Pretoria, South Africa \\ *Corresponding author, email: coetzeemj@ufs.ac.za \\ †Poster: 49th Annual Congress of the Federation of South African Societies of Pathology (FSASP), Pathtech, Durban, September 2009
}

A patient with Crimean-Congo haemorrhagic fever (CCHF) presented with a high white cell count and splenomegaly. Underlying chronic myeloid leukaemia was diagnosed. The management of this complex case was difficult, and the patient demised. This case illustrates that in patients with an acute febrile illness with haemorrhage, a thorough history and examination, as well as a high index of suspicion for concurrent conditions, is important.

Keywords: chronic myeloid leukaemia, Crimean-Congo haemorrhagic fever virus, leucocytosis, South Africa, tick-borne diseases

\begin{abstract}
Introduction
Since Crimean-Congo haemorrhagic fever (CCHF) was first described in South Africa in 1981, there have been at least 203 laboratory-confirmed cases. ${ }^{1,2}$ Even though it is a viral disease, the haematology laboratory is involved in the diagnosis and management because haematological coagulation parameters are of prognostic significance, ${ }^{3}$ and guide supportive treatment. Patients with underlying CCHF are not frequently worked up for a bleeding diathesis or haematological pathology initially, such as immune thrombocytopenia. CCHF can present with a myriad of clinical findings. Here we report a case of CCHF presenting with previously undiagnosed chronic myeloid leukaemia. The case report was approved by the Health Sciences Research Ethics Committee of the University of the Free State (approval number 177/08).
\end{abstract}

\section{Case report}

A significant number of $\mathrm{CCHF}$ cases have been reported from the Northern Cape province. ${ }^{4,5} \mathrm{~A} 35$-year-old male farm worker from the town of Prieska presented with fever, headache and myalgia after being bitten by a Hyalomma tick two days previously. ${ }^{6} \mathrm{He}$ was admitted to the isolation unit of Kimberley Hospital, with clinical and laboratory features of CCHF. ${ }^{7}$ These included a thrombocytopenia of $43 \times 10^{9} / \mathrm{l}$, a haemoglobin of $11.4 \mathrm{~g} / \mathrm{dl}$ and raised transaminases. The splenomegaly and a white cell count of $75 \times 10^{9} /$ I were considered unusual for CCHF. However, based on the history of exposure to ticks, in an area well-known for $\mathrm{CCHF}$, the clinical picture was compatible with CCHF. Taken together with concerns about health worker risks of infection, it was deemed essential to test for CCHF and to continue isolation procedures in the interim. CCHF was confirmed by reverse transcriptase polymerase chain reaction and serology at the National Institute for Communicable Diseases of the National Health Laboratory Service (NICD/NHLS). ${ }^{8}$

The white cell differential showed $1.29 \times 10^{9} /$ l blasts, $0.43 \times 10^{9} / \mathrm{I}$ promyelocytes, $5.16 \times 10^{9} / \mathrm{l}$ myelocytes, $0.43 \times 10^{9} / \mathrm{I}$ metamyelocytes, $0.86 \times 10^{9} / /$ band cells, $3.01 \times 10^{9} / /$ eosinophils and $3.44 \times 10^{9} / \mathrm{l}$ basophils. This is typical of chronic myeloid leukaemia (CML) in the chronic phase. The morphological diagnosis was confirmed in the referral haematology laboratory in Bloemfontein (Figures 1 and 2). Since the white cell count was raised due to the $C M L$, the finding by Swanepoel et al. ${ }^{3}$ that a white cell count $>10 \times 10^{\%} / \mathrm{l}$ in the first five days is a predictor of poor prognosis could probably not be applied strictly.

Fluorescent in situ hybridisation (Vysis LSI BCR/ABL Dual Color Single Fusions Translocation Probe Set, Abbott Molecular, Des Plaines, IL, United States) done on a blood smear demonstrated the $t(9 ; 21)(q 34.1 ; q 11.21)$ translocation pathognomonic of CML. The translocation between the $B C R$ and $A B L$ genes results in constitutively active tyrosine kinase that leads to the growth of $\mathrm{CML}$ clones. In an otherwise healthy patient, tyrosine kinase inhibitors are the treatment of choice. ${ }^{9}$ The leucocytosis alerted the laboratory to do a white cell differential count, leading to the confirmation of CML. The clinical picture and history of tick exposure in an endemic region suggested CCHF and prompted laboratory testing for CCHF, despite an initial high index of suspicion for an alternative diagnosis of a haematological condition. Appropriate infection control measures for a suspected viral haemorrhagic fever were immediately instituted to prevent nosocomial transmission.

Together with supportive care, ribavirin was given orally at a dosage of $30 \mathrm{mg} / \mathrm{kg}$ initially, followed by $15 \mathrm{mg} / \mathrm{kg}$ every six hours, and then $7.5 \mathrm{mg} / \mathrm{kg}$ every eight hours, as intravenous ribavirin is not available in South Africa. He received platelet transfusions as his platelet count continued dropping. By day five, his white cell count had risen to $120 \times 10^{9} / \mathrm{l}$, his haemoglobin dropped to $5.4 \mathrm{~g} / \mathrm{dl}$ and his platelet count dropped to $38 \times 10^{9} / \mathrm{l}$. Hydroxyurea at $2 \mathrm{~g}$ daily was started to reduce the leucocytosis. Allopurinol at $300 \mathrm{mg}$ daily was given to address tumour lysis. The patient unfortunately died on day six after admission from the complications of a combination of the diseases and treatment. A post-mortem was not performed. 


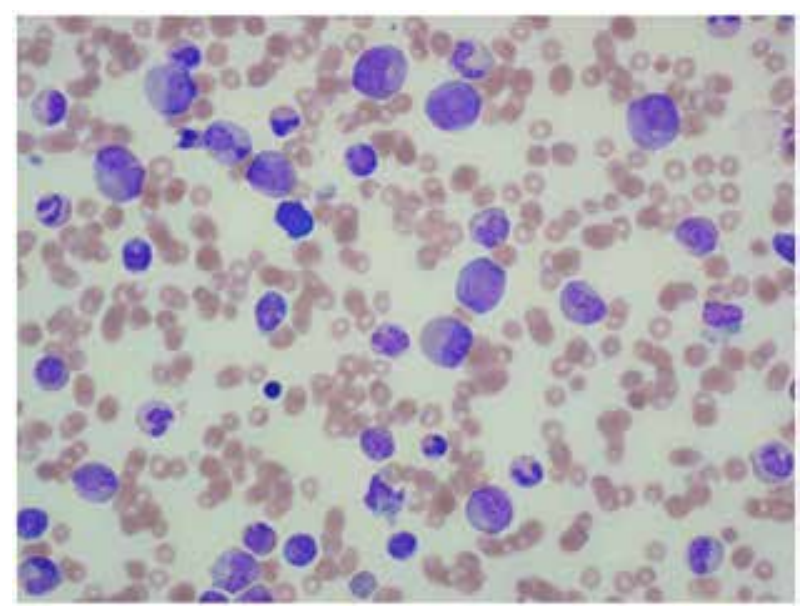

Figure 1: Peripheral blood smear of the patient at low $(50 \mathrm{x})$ magnification showing various stages of maturation of the myeloid series, from promyelocytes to band cells and eosinophils. This is typical of chronic myeloid leukaemia. No platelets are visible.

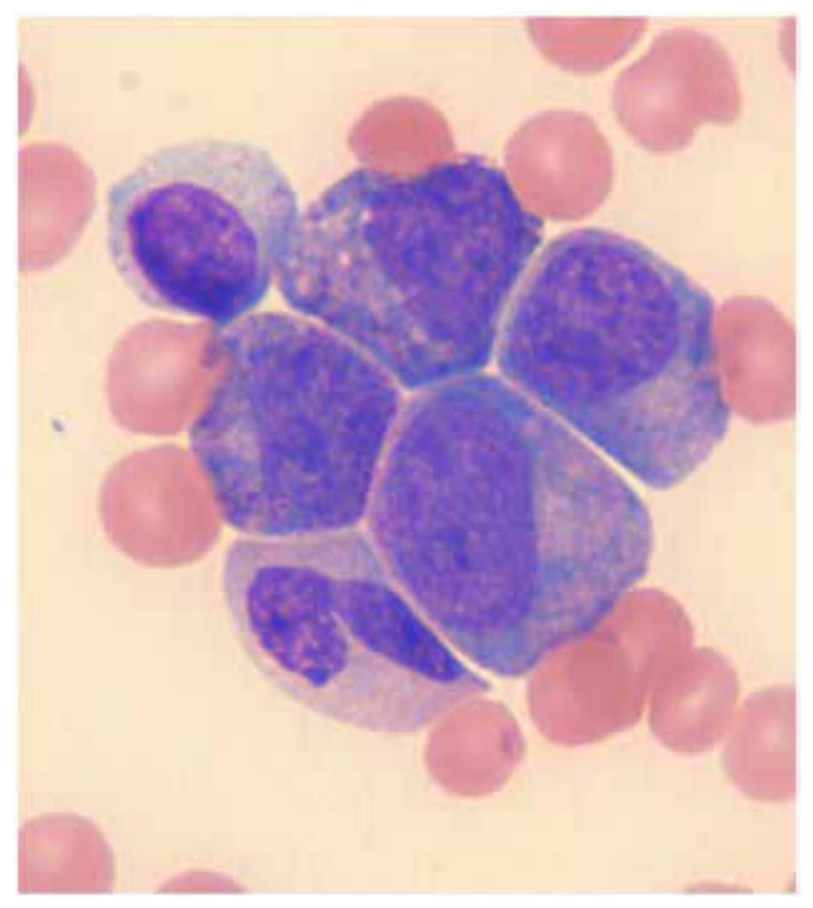

Figure 2: Peripheral blood smear of the patient at at high (100 x) magnification showing a blast, promyelocyte, an eosinophil precursor, band cell and lymphocyte.

\section{Discussion}

The patient would probably have presented with clinical CML a few months later, had he not contracted CCHF. The CML might have complicated the CCHF in a number of ways. The anaemia was probably worse and the high white cell count may have caused sluggish circulation. The lysis of CML cells might have caused urate nephropathy.

Karti et al. ${ }^{10}$ excluded any haematological malignancies in their series of 19 cases with suspected haemorrhagic fever by performing bone marrow aspirates. They reported haemophagocytosis, a condition distinct from CML. In the present case, we speculate that a combination of the direct effects of CML and $\mathrm{CCHF}$, and the treatment displayed adverse interactions.
CCHF virus infects the endothelium, ${ }^{11}$ leading to cytokine release, diffuse intravascular coagulopathy and thrombocytopenia. The myeloid precursors in the CML secrete inflammatory cytokines as well as adhesion molecules, ${ }^{12}$ thus compounding the vascular damage. It is unlikely that the patient had classical leucostasis as the white cell count was less than $100 \times 10^{9} / .^{12}$

Hydroxyurea and ribavirin are both metabolised in the liver. The liver damage caused by CCHF virus may have contributed to higher plasma concentrations of these drugs, with potentiation of adverse events of especially ribavirin.

The outcome of CCHF was compounded by the concurrent CML. $\mathrm{CCHF}$ has been diagnosed in the presence of a number of other conditions. Tezer et al. ${ }^{13}$ reported a case of a 14-year-old female who had concurrent visceral leishmaniasis. A bone marrow aspirate was done on her because of persistent splenomegaly and raised liver enzymes after clinical recovery from CCHF. Celikbas et al. ${ }^{14}$ reported a case of CCHF simulating acute appendicitis. Ergonul et al..$^{15}$ point out that CCHF might be confused with the HELLP (haemolytic anaemia elevated liver enzymes, low platelet count) syndrome in pregnancy. Doganci et al. ${ }^{16}$ mention that CCHF should be excluded in patients presenting with diffuse alveolar haemorrhage. Accurate and thorough epidemiological histories are important in all patients presenting with haemorrhage, especially in areas where viral haemorrhagic fevers are known to occur. Testing for CCHF must be carried out and infection control practices adhered to in all patients where the epidemiology and clinical course of illness are compatible with CCHF, even while there is strong consideration for other diseases.

Conflicts of interest - The authors have no commercial or other associations that might pose a conflict of interest.

Funding - The case report received no financial support.

Ackowledgements - Mrs Thea Brits of the Kimberley NHLS Laboratory reported the patient's first blood film and referred it for an opinion. Professor Vernon Louw of the Division of Clinical Haematology, Department of Internal Medicine, University of the Free State, Bloemfontein, South Africa, gave advice about the management of the chronic myeloid leukemia. We would like to thank all the doctors, nurses and other staff of Kimberley Hospital who were involved.

\section{ORCID}

Marius J Coetzee (iD http://orcid.org/0000-0003-2762-0966 Lucille H Blumberg (iD http://orcid.org/0000-0002-2828-7678 Janusz T Paweska (D) http://orcid.org/0000-0001-8776-7519 Robert Swanepoel (D) http://orcid.org/0000-0003-2538-3290 André de Kock (iD http://orcid.org/0000-0002-2910-1273

\section{References}

1. National Institute for Communicable Diseases. Provisional laboratory indicators for NHLS and NICD, South Africa, corresponding periods 1 January - 31 March 2015/2016. NICD-NHLS Communicable Diseases Surveillance Bulletin 2016;14:54 [cited 2017 Jul 24]. Available from: http://www.nicd.ac.za/wp-content/uploads/2017/03/CommDisBull142-June2016_amend-5-July.pdf

2. NICD-NHLS Centre for Emerging and Zoonotic Diseases, Groote Schuur Hospital Infectious Diseases. Crimean-Congo haemorrhagic fever in the Western and Northern Cape provinces. NICD-NHLS Communicable Diseases Communique 2017;16:2 [cited 2017 Jul 24]. Available from: http://www.nicd.ac.za/wp-content/uploads/2017/03/ NICD-Communicable-Diseases-Communique_January2017_final.pdf 
3. Swanepoel R, Gill DE, Shepherd AJ, et al. The clinical pathology of Crimean-Congo hemorrhagic fever. Reviews of infectious diseases 1989;11:S794-S800 [cited 2017 Mar 01]. Available from: https://academic.oup.com/cid/article-abstract/11/Supplement_4/ S794/341777/The-Clinical-Pathology-of-Crimean-Congo?redirected From=fulltext

4. Fisher-Hoch SP, McCormick JB, Swanepoel R, et al. Risk of human infections with crimean-congo hemorrhagic fever virus in a South African rural community. Am J Trop Med Hyg. 1992;47:337-45 [cited 2017 Mar 01]. Available from: https://www.ajtmh.org/content/ journals/10.4269/ajtmh.1992.47.337

5. National Institute for Communicable Diseases. Congo Fever confirmed in Northern Cape farmer. NHLS Alerts 19 November 2014 [cited 2017 Jul 24]. Available from: http://nhls.ac.za/?page=alerts\&id $=5 \&$ rid $=454$

6. IOL. Congo fever patient dies. IOLcoza, 2006 Dec 22 [cited 2017 Mar 01]. Available from: https://www.iol.co.za/news/south-africa/congofever-patient-dies-308485

7. Swanepoel R, Shepherd AJ, Leman PA, et al. Epidemiologic and clinical features of crimean-congo hemorrhagic fever in Southern Africa. Am J Trop Med Hyg. 1987;36:120-32 [cited 2017 Mar 01]. Available from: https://www.ajtmh.org/content/journals/10.4269/ ajtmh.1987.36.120

8. Paweska J, Leman P, Blumberg L. Viral haemorrhagic fevers, South Africa, 2006. Communicable Disease Surveillance Bulletin. 2007;6:6 [cited 2017 Jul 24]. Available from: http://www.nicd.ac.za/assets/files/ CommDisBullMarch07.pdf

9. Louw VJ, Dreosti L, Ruff P, et al. Recommendations for the management of adult chronic myeloid leukaemia in South Africa. S Afr Med J. 2011;101:840-6 [cited 2017 Mar 01]. Available from: https://www.samj.org.za/index.php/samj/article/view/5223

10. Karti SS, Odabasi Z, Korten V, et al. Crimean-Congo hemorrhagic fever in Turkey. Emerg Infect Dis. 2004;10:1379-84 [cited 2017 Mar 01]. Available from: https://wwwnc.cdc.gov/eid/article/10/8/pdfs/030928.pdf
11. Ergonul O. Crimean-Congo haemorrhagic fever. Lancet Infect Dis. 2006;6:203-14 [cited 2017 Mar 01]. Available from: $\quad$ https://www.ncbi.nlm.nih.gov/pubmed/15496237 https://doi.org/10.1016/S1473-3099(06)70435-2

12. Porcu P, Cripe LD, Ng EW, et al. Hyperleukocytic leukemias and leukostasis: a review of pathophysiology, clinical presentation and management. Leukemia \& Lymphoma. 2000;39:1-18 [cited 2017 Mar 01]. Available from: https:// www.tandfonline.com/doi/pdf/10.3109/10428190009053534 https://doi.org/10.3109/10428190009053534

13. Tezer H, Tavil B, Sucakl? IA, et al. Concurrent crimean-Congo hemorrhagic fever and visceral leishmaniasis in a Turkish girl. Vector Borne Zoonotic Dis. 2011;11:743-5 [cited 2017 Mar 01]. Available from: https://online.liebertpub.com/doi/abs/10.1089/vbz.2010.0092 https://doi.org/10.1089/vbz.2010.0092

14. ÇelikbaşA, Ergönül O, Dokuzoğuz B, et al. Crimean Congo hemorrhagic fever infection simulating acute appendicitis. J Infect. 2005;50:363-5 [cited 2017 Mar 01]. Available from: https://www.journalofinfection. com/article/S0163-4453\%2804\%2900120-3/abstract https://doi.org/10.1016/j.jinf.2004.05.020

15. Ergonul O, Celikbas A, Yildirim U, et al. Pregnancy and CrimeanCongo haemorrhagic fever. Clin Microbiol Infect. 2010;16:64750 [cited 2017 Mar 01]. Available from: https://onlinelibrary. wiley.com/doi/10.1111/j.1469-0691.2009.02905.x/full https://doi.org/10.1111/j.1469-0691.2009.02905.x

16. Doganci L, Ceyhan M, Tasdeler NF, et al. Crimean Congo hemorrhagic fever and diffuse alveolar haemorrhage. Trop Doct. 2008;38:252-4 [cited 2017 Mar 01]. Available from: https://journals. sagepub.com/doi/abs/10.1258/td.2008.070406?url_ver=Z39.882003\&rfr_id=ori:rid:crossref.org\&rfr_dat $=c r \_p u b \% 3 \mathrm{dpubmed}$ https://doi.org/10.1258/td.2008.070406

Received: 07-03-2017 Accepted: 20-06-2017 